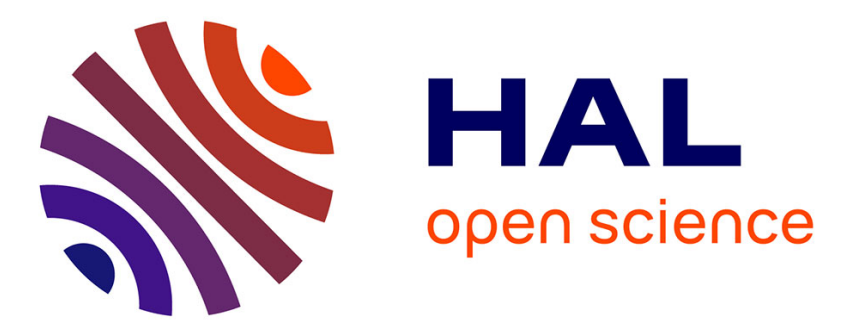

\title{
Compact 180-kV Marx generator triggered in atmospheric air by femtosecond laser filaments
}

Léonid Arantchouk, G Point, Yohann Brelet, Jean Larour, Jérôme Carbonnel, Yves-Bernard André, A Mysyrowicz, Aurélien Houard

\section{- To cite this version:}

Léonid Arantchouk, G Point, Yohann Brelet, Jean Larour, Jérôme Carbonnel, et al.. Compact 180-kV Marx generator triggered in atmospheric air by femtosecond laser filaments. Applied Physics Letters, 2014, 104, pp.103506. 10.1063/1.4868227 . hal-01118158

\section{HAL Id: hal-01118158 \\ https://hal-ensta-paris.archives-ouvertes.fr/hal-01118158}

Submitted on 18 Feb 2015

HAL is a multi-disciplinary open access archive for the deposit and dissemination of scientific research documents, whether they are published or not. The documents may come from teaching and research institutions in France or abroad, or from public or private research centers.
L'archive ouverte pluridisciplinaire HAL, est destinée au dépôt et à la diffusion de documents scientifiques de niveau recherche, publiés ou non, émanant des établissements d'enseignement et de recherche français ou étrangers, des laboratoires publics ou privés. 


\title{
Compact 180-kV Marx generator triggered in atmospheric air by femtosecond laser filaments
}

\author{
L. Arantchouk ${ }^{1, a)}$, G. Point ${ }^{2}$, Y. Brelet ${ }^{2}$, J. Larour $^{1}$, J. Carbonnel$^{2}$, \\ Y.-B. André2 ${ }^{2}$ A. Mysyrowicz ${ }^{2}$, A. Houard ${ }^{2}$ \\ ${ }^{1}$ Laboratoire de Physique des Plasmas - Ecole Polytechnique, CNRS - 91128 Palaiseau, France \\ ${ }^{2}$ Laboratoire d'Optique Appliquée - ENSTA ParisTech, Ecole Polytechnique, CNRS - 91761 Palaiseau, \\ France
}

\begin{abstract}
We developed a compact Marx generator triggered in atmospheric air by a single femtosecond laser beam undergoing filamentation. Voltage pulses of $180 \mathrm{kV}$ could be generated with a subnanosecond jitter. The same laser beam was also used to initiate simultaneously guided discharges up to $21 \mathrm{~cm}$ long at the output of the generator.
\end{abstract}

Proposed in 1924 by Erwin Otto Marx, the Marx generator is now commonly used in high-energy physics (electron and ion beam acceleration, pinch plasma, microwave generation, etc) and for pulse power applications (industry, medical, environment, agriculture, etc). Marx generator (MG) consists in a set of parallel stages including capacitor banks and switches. The capacitors are first charged in parallel to a voltage $\mathrm{V}_{0}$, and are then connected in series through closing switches. In the traditional operation mode, commutation of the lower stage induces an overvoltage and self breakdown on the following stages. In this way, all individual switches close, producing an output voltage theoretically given by the product of the charging voltage $\mathrm{V}_{0}$ by the number of stages $\mathrm{N}: \mathrm{V}_{\mathrm{MG}}=\mathrm{NV}_{0}$. In practice, due to the intrinsic and stray capacitance of the switches, the voltage multiplication across the switch gap is lower than the theoretical value. This results in rather complex construction solutions and reduction of the generator efficiency.

The switch performance is related to its design and triggering conditions. The reader is directed to ref. ${ }^{1-7}$ to find some practical realizations of Marx generators with high-level characteristics. Several techniques were developed to improve the spark gap (SG) performances: placing the gap in an appropriate gas mixture at high pressure (up to 20 bars), inserting Marx modules in metallic housing to increase the stray capacitance or using a line-of-sight geometry to obtain a stable Marx erection due to ultra-violet photo-ionization.

In several publications a jitter of $1 \mathrm{~ns}$ or less has been achieved by means of rather complicated methods. In ref. ${ }^{8}$ the Marx stages are operated very close to self-break regime (95\%) in dry air at 4 bars. A KrF excimer laser beam passes through a metal mesh installed in the switch electrode holes. Laser interaction with the mesh produces photoelectrons, which in turn trigger a discharge in the two adjacent switches simultaneously. In ref. ${ }^{9}$ the spark gaps breakdown was considerably accelerated by connecting the individual stages with coupling capacitors, while a needle auxiliary corona discharge was used to reduce the breakdown temporal jitter. A subns jitter was reported in ${ }^{10}$ with a mini-Marx using a UV laser with a gas mixture containing SF $_{6}$ at 3 bars in the gap switches. A similar jitter was also reported in ref. ${ }^{11}$.

Triggering the gap switch using femtosecond laser filament is based on a different concept. Laser filamentation is a nonlinear phenomenon appearing during propagation of intense femtosecond laser pulses provided their peak power exceeds a critical threshold $\mathrm{P}_{\mathrm{cr}}$ of the order of $5 \mathrm{GW}$ in air (at $800 \mathrm{~nm}$ ). A dynamic competition between nonlinear self-focusing and multiphoton ionization leads to a contraction of the laser beam into thin light channels of $100 \mu \mathrm{m}^{12}$. This filamentary laser pulse leaves in its wake a long plasma string with an electron density of $10^{16} \mathrm{~cm}^{-3}$ that has the ability to trigger and guide electric discharges over several meters ${ }^{13-16}$. In ref. ${ }^{17}$ we presented a gap switch triggered with femtosecond laser filaments. A sub-nanosecond jitter was obtained in atmospheric air even with a 1-cm gap when the switch was charged at $70 \%$ of the self breakdown limit. According to ref. ${ }^{18}$, the characteristic time for discharge establishment in a $10 \mathrm{~mm}$ spark gap in atmospheric air is about $\mathrm{T}_{\mathrm{SG}} \sim 4 \mathrm{~ns}$. If several SGs are triggered with the same laser beam and if their jitter $<<$ $\mathrm{T}_{\mathrm{SG}}$, one should obtain then an ideal Marx generator with simultaneous switching of all stages. This result has been the motivation to develop a MG triggered by a single filamentary laser beam.

In this experiment the ENSTAmobile laser with a maximum energy per pulse of $300 \mathrm{~mJ}$ was used to create the plasma filaments in air ${ }^{17,19}$. The laser pulse duration was fixed to $700 \mathrm{fs}$ corresponding to a peak power about $85 \mathrm{P}_{\mathrm{cr}}$. In this regime, the laser beam focused by a $5 \mathrm{~m}$ focal lens produced a tight bundle of $\sim 50$ plasma filaments extending over $1.5 \mathrm{~m}$ before and $0.5 \mathrm{~m}$ after the geometrical focus of the beam. The diameter of this plasma column was measured to vary between 2 and $5 \mathrm{~mm}$. A two meter long plasma channel allows

\footnotetext{
a) Author to whom correspondence should be addressed. Electronic mail: leonid.arantchouk@1pp.polytechnique.fr.
} 
triggering practically simultaneously all the gap switches installed in line-of-sight geometry on the laser propagation axis.

A single stage of our MG (Fig. 1) is composed of two parts. The first one presents six 2 nF "door knob" ceramic capacitors in parallel connected by two metal discs. The second part is a spark gap made by two 35-mm diameter cylindrical electrodes with $5 \mathrm{~mm}$ radius curved border. The laser beam enters the spark gap through a 3-4.5 mm diameter hole drilled axially in the electrodes. The inter-electrode gap D is fixed by a Plexiglas ring which serves at the same time as a spacer between the Marx's stages. We worked with inter-electrode spacing D $=11.25 \mathrm{~mm}$ and $12 \mathrm{~mm}$ corresponding respectively to self-breakdown voltages $\mathrm{V}_{\text {cr }}$ of $34 \mathrm{kV}$ and $36 \mathrm{kV}$. A DC power supply charged the stage capacitors to a voltage $\mathrm{V}_{0}=30 \mathrm{kV}$, corresponding to a self break spacing $\mathrm{D}=$ $9.7 \mathrm{~mm}$. In practice, to avoid breakdown hazard and reduce the pre-fire safety factor it is necessary to work as far as possible from the self-breakdown limit. The assembled stages were successively slided over six nylon allthread rods and were tightened up with nuts. Our design allows arranging the gap switch holes in an optical lineof-sight with a good precision so that the laser beam passes through all the stages.

Our Marx generator is composed of up to 6 stages, with a diameter of $250 \mathrm{~mm}$ and a total length of 55 $\mathrm{cm}$. It generates up to $180 \mathrm{kV}$ output voltage. The authors of ref. ${ }^{20}$ have proposed to classify MG into three categories according to their overall parameters. In accordance with such parameters our MG belongs to the ultra compact designs, but higher output voltage let us relate the generator to the compact category.

To characterize the Marx generator we studied two parameters: the runtime, which is the delay between the laser triggering and the breakdown of the generator, and the jitter, defined as the standard deviation of the runtime. The statistics presented here were based on 10-15 shots. For high voltage measurements we used a voltage divider made up from HVR resistors (HVR International). The discharge current was monitored with a current viewing resistor (CVR) in series with the load, and the laser firing time was monitored with a fast photodiode.

The output voltage signal of the 6-stages Marx with $\mathrm{V}_{0}=27 \mathrm{kV}$ presents an exponential decay $\tau=\mathrm{RC} \approx$ $5 \mu$ s when the generator discharges on a high resistance load $\mathrm{R}_{\text {load }}=2.7 \mathrm{k} \Omega$ (Fig. 2(a)). The front edge of the voltage pulse is shown in Fig. 2(b). To avoid influence of electromagnetic noises at the discharge beginning, we define the time $\mathrm{T}_{\text {Marx }}$ corresponding to the 50-percent point of the voltage maximum as a reference for the Marx discharge beginning. The point $\mathrm{T}_{0}=0$ corresponds to the laser beam arrival. Runtime delay corresponds then to $\mathrm{T}_{\text {Marx }}-\mathrm{T}_{0}$. We measured a voltage amplitude corresponding with $5 \%$ precision to the value $\mathrm{NV}_{0}$.

Runtime and jitter for the 6-stages Marx are presented in Fig. 3 as a function of the normalized breakdown voltage $\mathrm{V}_{0} / \mathrm{V}_{\mathrm{cr}}$. The runtime decreases from 60 ns to 20 ns with increase of $\mathrm{V}_{0} / \mathrm{V}_{\text {cr }}$ from $60 \%$ to $80 \%$. The jitter is less or about $1 \mathrm{~ns}$ for $\mathrm{V}_{0} / \mathrm{V}_{\mathrm{cr}} \geq 65 \%$. We also measured the Marx performances when the laser was shot from the output side of the Marx. A runtime about $3 \mathrm{~ns}$ longer was observed in this case, while the jitter remained unchanged. Several configuration of spark gap holes were tested, with a constant diameter for all stages or with decreasing diameter ranging from 4.5 to $3 \mathrm{~mm}$. Finally the best characteristics were obtained with the hole configuration $\varnothing 3 \mathrm{~mm}$, as shown in Fig. 3 .

To confirm the effect of the filament in the triggering process we performed a test while blocking the laser beam at the third stage of the MG. We observed in this case an increase of the runtime from 60 to $350 \mathrm{~ns}$ with Marx charged up to $60 \%$ self-breakdown voltage.

Finally we determined the minimum laser energy required to maintain a subnanosecond jitter in the generator. With a charging voltage $\mathrm{V}_{0}=27 \mathrm{kV}$ we were able to keep the same runtime of 20-25 ns with a ns jitter by decreasing the laser energy down to $30 \mathrm{~mJ}$, for a pulse duration of $700 \mathrm{fs}$. This corresponds to a peak power of $43 \mathrm{GW}$, which is close to single filamentation regime. Similar characteristics were also obtained with laser energy of $6 \mathrm{~mJ}$ with a pulse duration of $100 \mathrm{fs}(60 \mathrm{GW})$.

The laser induced filament beam was used not only to trigger the Marx, but also to produce a guided discharge (GD) at the output of the generator. For this purpose a rather important output load resistance was chosen, to ensure the voltage keeps a high value for a reasonably long time. The advantage of this setup is that the laser is automatically synchronized with the high voltage pulse. To produce a long guided discharge a second electrode $E_{2}$ was installed at a distance $L_{d}$ from the Marx output electrode $E_{1}$ as shown in Fig. 1(b). The laser beam was aligned so that the filaments touched tangentially both electrodes. The second electrode was loaded on a resistance $\mathrm{R}_{\mathrm{d}} \sim 300 \Omega$.

Typical signals of the discharge current and the output MG voltage are depicted in Fig. 4. Up to the moment of the long discharge beginning, the $M G$ discharges through the high load $\mathrm{R}_{\text {load }}=2.7 \mathrm{k} \Omega$. After breakdown occurs between $\mathrm{E}_{1}$ and $\mathrm{E}_{2}$, a current peak appears over the quasi-pedestal created by the previous high resistance discharge. Since the resistance of the long discharge is relatively small, this current peak amplitude is defined by the resistance $R_{d}=300 \Omega$ and by the Marx voltage when the discharge occurs. In our experiments the long discharge maximal current was measured to be $\sim 450 \mathrm{~A}$. 
We studied the time delay between Marx voltage pulse and appearance of the guided discharge for two configurations. In the first one, the laser passed through the Marx first and then through the region of the guided discharge (MGD configuration). In the second geometry the laser passed between the two long discharge electrodes first and then entered into the MG (GDM configuration). As it was mentioned above, the Marx characteristics are weakly sensitive to the laser direction.

The measured delays between the Marx output voltage and the guided discharge are shown in Fig. 5 as a function of the reduced discharge field $E_{\text {disch }}$ for both configurations. Measurements were performed with discharge lengths ranging from $12 \mathrm{~cm}$ to $21 \mathrm{~cm}$, showing that the delay mostly depends on $\mathrm{E}_{\text {disch }}$ rather than on the discharge length $\mathrm{L}_{\mathrm{d}}$. The best triggering characteristics were achieved when the laser enters the generator from its output side (GDM configuration) as shown in Fig. 5(b). In this configuration delay and jitter are almost two times smaller than for the other configuration. As a reference, a delay Marx-Discharge smaller than $300 \mathrm{~ns}$ with a jitter less than $60 \mathrm{~ns}$ is measured when the discharge field is higher than $10 \mathrm{kV} / \mathrm{cm}$. This higher guiding efficiency in GDM geometry can be explained by the higher laser energy participating in the preparation of the guided discharge, since about 50\% of the laser energy is blocked by the sparks gaps holes of the Marx.

Finally one should mention that the discharge triggering characteristics are sensitive to output Marx voltage polarity. The maximal distance $\mathrm{L}_{\mathrm{d}}=21 \mathrm{~cm}$ was only observed with a positive polarity.

In conclusion, we have presented a design of Marx generator triggered by means of laser filaments produced in air by a TW femtosecond laser source. High voltage pulses of $180 \mathrm{kV}$ with a runtime $\leq 20 \mathrm{~ns}$ and a temporal jitter $\leq 1 \mathrm{~ns}$ could be produced with a charging voltage higher than $70 \%$ of self-breakdown. We determined that the Marx performance in terms of jitter and delay start to degrade when the laser input is lower than $50 \mathrm{GW}$.

The same bundle of laser filaments was also used to produce guided discharges up to $21 \mathrm{~cm}$ long. The delay between the discharge and the Marx pulse is mostly dependent on the ratio $\mathrm{E}_{\mathrm{disch}}=\mathrm{V}_{\mathrm{Marx}} / \mathrm{L}_{\mathrm{d}}$. The best discharge characteristics were observed using a geometry where the laser beam enters from the output generator side and with a positive voltage polarity.

\section{ACKNOWLEDGMENTS}

This work was supported by the French Direction Générale de 1'Armement (grant EPAT n²007 95091 and grant DGA-Ecole Polytechnique 2009). The authors would like to thank J.-L. Charles for his technical help.

\section{REFERENCES}

${ }^{1}$ R.E. Beverly III and R.N. Campbell, Rev. Sci. Instrum. 65, 259 (1994).

${ }^{2}$ M.M. Kekez, Rev. Sci. Instrum. 62, 2923 (1991).

${ }^{3}$ B. Cadilhon, L. Pecastaing, T. Reess and A. Gibert, IET Electr. Power Appl. 2, 248 (2008).

${ }^{4}$ S.E. Calico, M.C. Scott and M.C. Clark, Pulsed Power Conf. IEEE, Digest of Techn. Papers, pp. 1536-1541 (1997).

5 A.J. Dragt and J.M. Elizondo, Pulsed Power Plasm. Science, PPPS-2001, Digest of Techn. Papers, pp.15551558, vol.2 (2001).

${ }^{6}$ D. Goerz, T. Ferriera, D. Nelson, R. Speer, M. Wilson, in Digest Technical Papers, IEEE-PPPS2001, p.628631 (2001).

7 A.A. Neuber, Y.J. Chen, J.C. Dickens and M. Kristiansen, Pulsed Power Conf. IEEE, pp 1203-1206 (2005).

${ }^{8}$ H. Kusama and T. Yagi, IEEE Trans. Plasma Sci. 25, 1431 (1997).

${ }^{9}$ E. Gygi and F. Schneider, Sci. Rept. CERN. AR64:46, (1964).

${ }^{10}$ J.C. Kellog, Pulsed Power Conf. IEEE, p1175-1178 (1999).

${ }^{11}$ J.R. Mayes, W. J. Carey, W.C. Nunnally, L. Altgilbers, Pulsed Power Plasm. Science, PPPS-2001, Digest of Techn. Papers, pp. 471-474 (2001).

${ }^{12}$ A. Couairon and A. Mysyrowicz, Phys. Rep. 441, 47 (2007).

${ }^{13}$ H. Pépin, D. Comtois, F. Vidal, C. Y. Chien, A. Desparois, T. W. Johnston, J. C. Kieffer, B. La Fontaine, F. Martin, F. A. M. Rizk, C. Potvin, P. Couture, H. P. Mercure, A. Bondiou-Clergerie, P. Lalande and I. Gallimberti, Phys. Plasmas 8, 2532 (2001).

${ }^{14}$ F. Vidal, D. Comtois, H. Pépin, T. Johnston, C.-Y. Chien, A. Desparois, J.-C. Kieffer, B. La Fontaine, F. Martin, F. A.M. Rizk, H. P. Mercure, C. Potvin, C. R. Physique 3, 1361 (2002).

${ }^{15}$ B. Forestier, A. Houard, I. Revel, M. Durand, Y. B. André, B. Prade, A. Jarnac, J. Carbonnel, M. Le Nevé, J. C. de Miscault, B. Esmiller, D. Chapuis, and A. Mysyrowicz, AIP Advances 2, 012151 (2012).

${ }^{16}$ J.-F. Daigle, F. Théberge, P. Lassonde, J.-C. Kieffer, T. Fujii, J. Fortin, M. Châteauneuf and J. Dubois, Appl. Phys. Lett. 103, 184101 (2013).

${ }^{17}$ L. Arantchouk, A. Houard, Y. Brelet, J. Carbonnel, J. Larour, Y.-B. André, and A. Mysyrowicz, Appl. Phys. Lett. 102, 163502 (2013).

${ }^{18}$ G.A. Mesyats, Pulsed Power, New York: Kluver Academic/Plenum (2004). 
${ }^{19}$ Y. Brelet, A. Houard, G. Point, B. Prade, L. Arantchouk, J. Carbonnel, Y.-B. Andre, M. Pellet, A. Mysyrowicz, Appl. Phys. Lett. 101, 264106 (2012).

${ }^{20}$ B. Martin, P. Raymond, J. Wey, Rev. Sci. Instrum. 77, 043505 (2006).

\section{FIGURES}
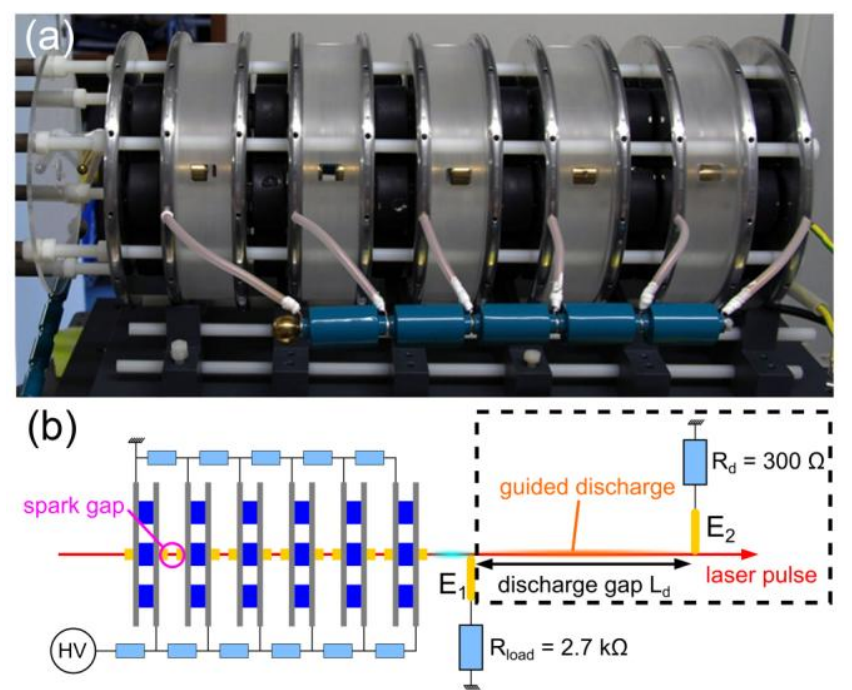

FIG. 1. (a) Photography of the 6-stages Marx generator. (b) Schematic setup of the Marx with the configuration for long discharge guiding as insert.
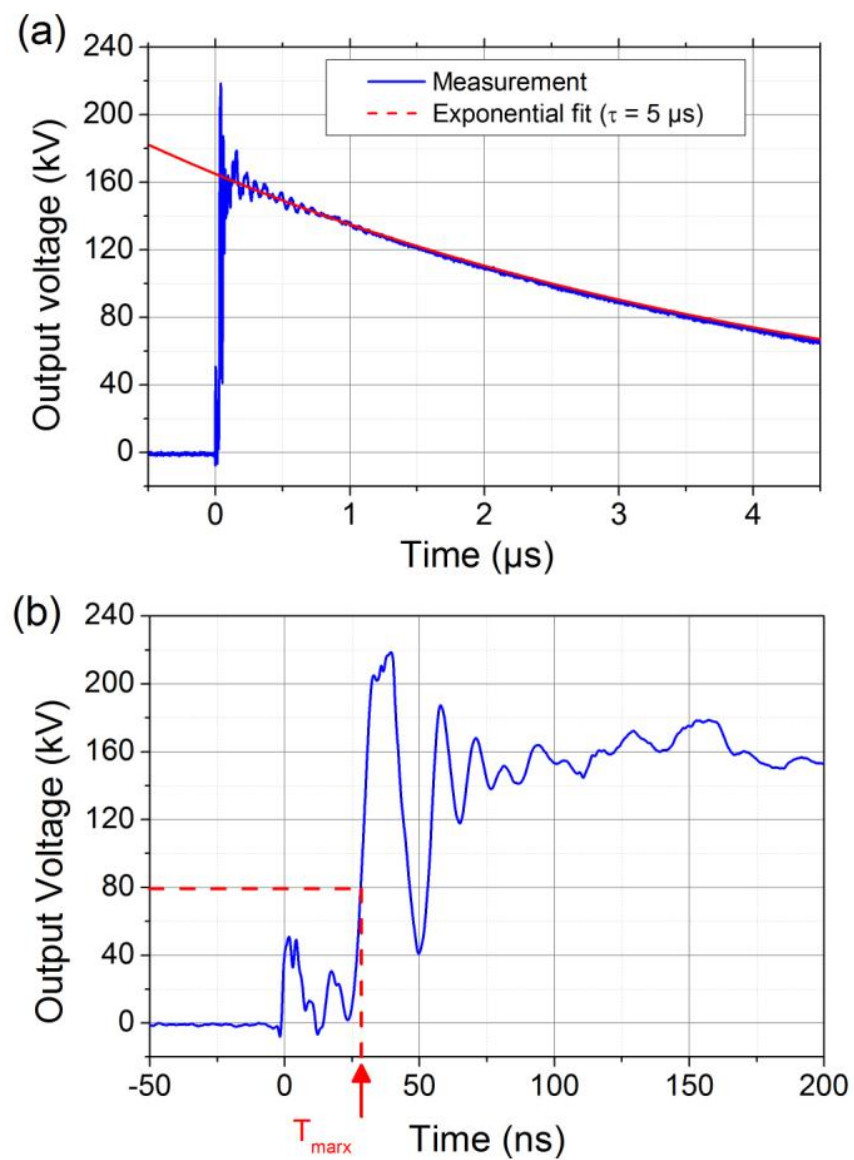

FIG. 2 (a) Output voltage signal generated by the Marx with stage charge $V_{0}=27 \mathrm{kV}$. (b) Rising edge of the voltage pulse. 
(a)

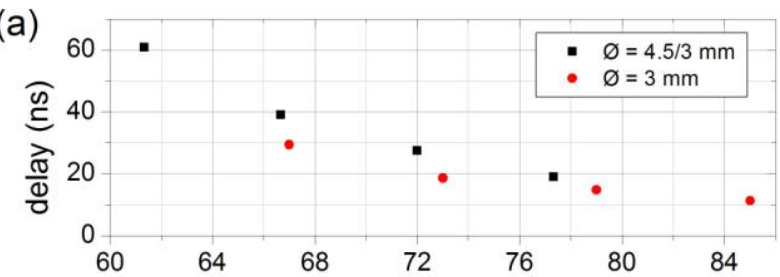

(b) 4 .

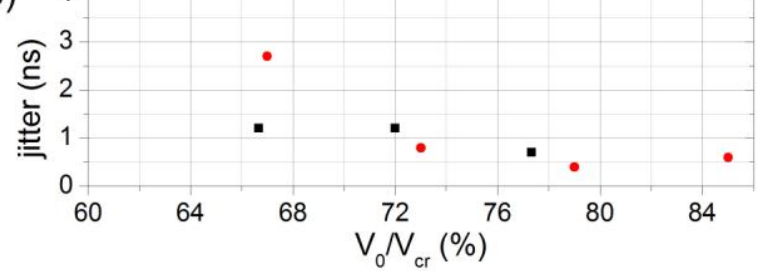

FIG.3 Runtime delay (a) and jitter (b) of the Marx in the hole configuration $\varnothing 4.5 \mathrm{~mm}$ to $\varnothing 3 \mathrm{~mm}$ (black squares) and with the configuration $\varnothing 3 \mathrm{~mm}$ (red dots).

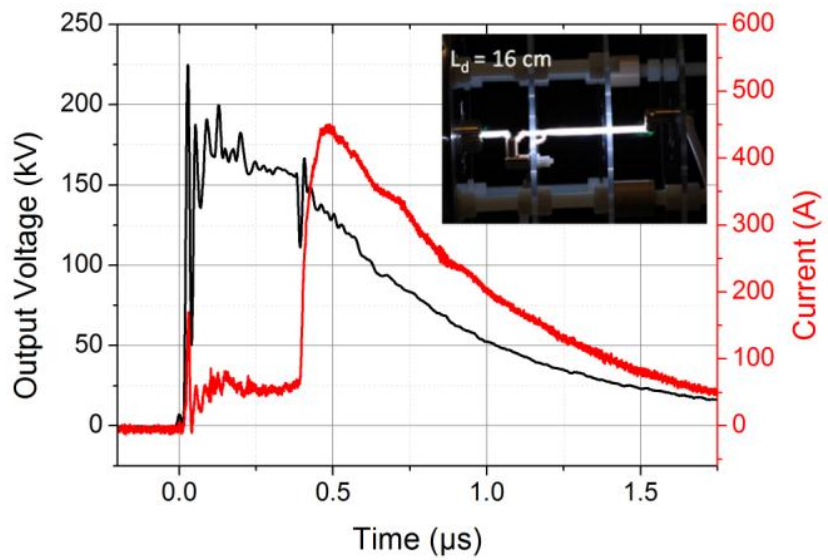

FIG. 4 Signals of the MG output voltage and current with the guided discharge. Inset shows a side picture of the guided discharge. 

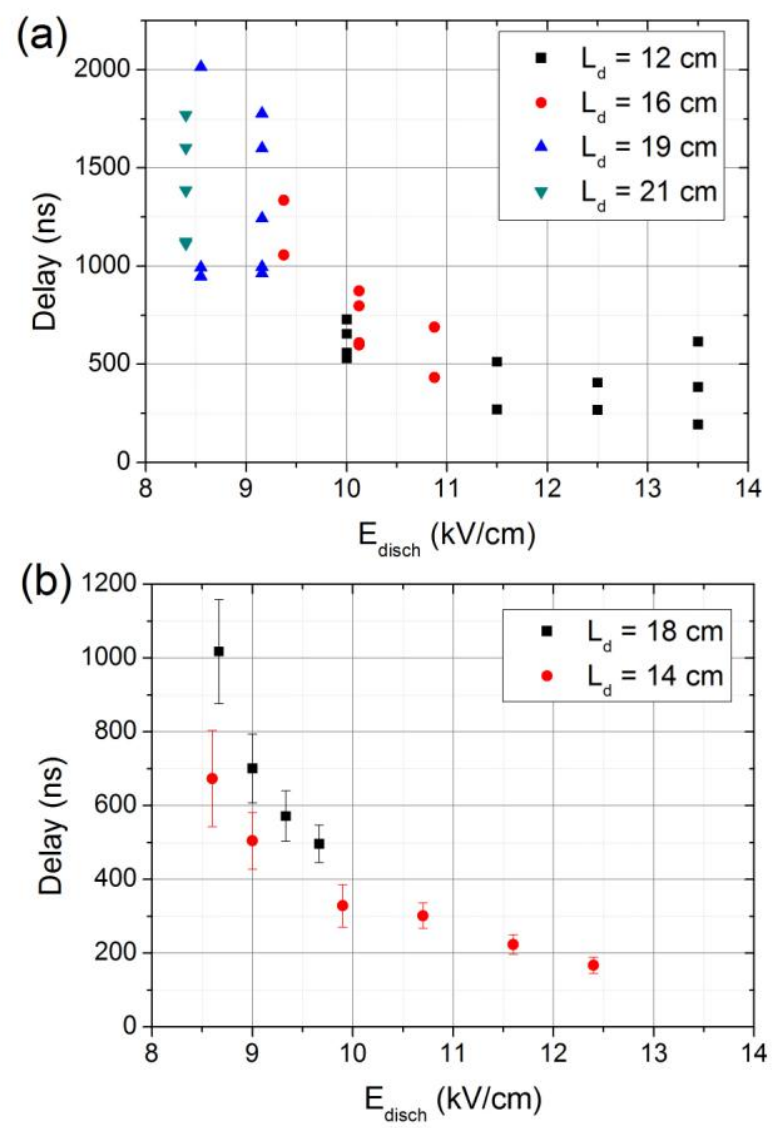

FIG. 5 Delay Discharge-Marx as a function of discharge field $E_{\text {disch }}=V_{\text {Marx }} / L_{d}$ for the MGD configuration (a) and for GDM configuration (b). The discharge length $\mathrm{L}_{\mathrm{d}}$ ranged from 12 to $21 \mathrm{~cm}$. 